\title{
Insufficient evidence on whether to restore root-filled teeth with single crowns or routine fillings
}

\author{
Abstracted from \\ Sequeira-Byron P, Fedorowicz Z, Carter B, Nasser M, Alrowaili EF \\ Single crowns versus conventional fillings for the restoration of root-filled teeth (Review). \\ Cochrane Database Syst Rev 2015; 9: CD009109 \\ Address for correspondence: Luisa Fernandez Mauleffinch, Managing Editor, \\ Cochrane Oral Health Group, School of Dentistry, The University of Manchester, \\ JR Moore Building, Oxford Road, Manchester, M13 9PL, UK. E-mail: luisa.fernandez@manchester.ac.uk
}

\section{Question: What are the effects of restoration of endodontically treated teeth (with or without post and core) by crowns versus conventional filling materials?}

Data sources Medline, Cochrane Oral Health Group's Trials Register, Cochrane Central Register of Controlled Trials, Embase, CINAHL, LILACS.

Study selection Three authors independently assessed the abstracts of studies resulting from the above searches which compared indirect restorations of single endodontically treated teeth (ETT) to direct restoration of single ETT.

Data extraction and synthesis Titles and abstracts of all reports identified through the electronic searches were assessed independently by two authors with any disagreements on eligibility resolved by a third reviewing author based on agreed upon inclusion and exclusion criteria. Study quality was assessed using the Cochrane risk of bias tool. Catastrophic failure of the restored tooth or restoration leading directly to extraction was the primary outcome measure. Secondary outcome measures included patient quality of life, incidence of recurring caries, periodontal health status and cost of the use of different interventions. Data analysis was carried out using the, 'treatment as allocated', patient population, expressing estimates of intervention effect for dichotomous data as risk ratios, with $95 \%$ confidence intervals $(\mathrm{Cl})$.

Results One trial which was judged to be at high risk of performance, detection and attrition bias was included. There was no clear difference between the crown and composite group and the composite only group for non-catastrophic failures of the restoration ( $1 / 54$ versus $3 / 53 ; \mathrm{RR} 0.33 ; 95 \% \mathrm{Cl} 0.04$ to 3.05$)$ or failures of the post (2/54 versus $1 / 53$; RR $1.96 ; 95 \% \mathrm{Cl} 0.18$ to 21.01 ) at three years. The quality of the evidence for these outcomes was judged to be very low. There was no evidence available for any secondary outcomes. Conclusions Insufficient evidence exists to assess the effects of crowns compared to conventional fillings for the restoration of rootfilled teeth. Until more evidence becomes available, clinicians should

This paper is based on a Cochrane Review published in the Cochrane Library 2015, issue 9 (see www.thecochranelibrary.com for information). Cochrane Reviews are regularly updated as new evidence emerges and in response to feedback, and the Cochrane Library should be consulted for the most recent version of the review. continue to base decisions about how to restore root-filled teeth on their own clinical experience, whilst taking into consideration the individual circumstances and preferences of their patients.

\section{Commentary}

Endodontically treated teeth (ETT) pose a number of problems to the restorative dentist. ETT often suffer considerable tooth structure loss from caries, fracture, endodontic instrumentation, previous restorations, crown and post space preparations. ${ }^{1-2}$ Such can be the level of tooth structure destruction that the classic restorative literature even referred to these teeth as 'mutilated'. ${ }^{3}$

With this amount of absent tooth structure it is necessary to spend some time considering how to restore these teeth. Any restoration must maintain tooth integrity and function, coronal and apical seal and when necessary achieve an aesthetic result. ${ }^{4-6}$ Yet, in spite of these aims it is well known that ETT with minimal coronal tooth structure face a poor prognosis and tend to fail due to coronal microleakage, dislodgement of the post and core and/or crown, if not by catastrophic root fracture when restored with crowns. ${ }^{6-8}$

It is commonly accepted that ETT with minimal coronal tooth structure ought to be restored with crowns, however controversy exists when considering how to restore ETT with almost intact coronal structure. This Cochrane systematic review asks whether it is better to restore ETT with any type of conventional direct filling material, or conversely with any type of indirect restoration, with or without post and cores.

Classic prosthodontic teaching would recommend restoring posterior ETT with crowns over conventional direct fillings where possible due to significantly higher survival statistics reported for posterior ETT with cuspal coverage. ${ }^{9}$ However, as with much of the prosthodontic literature we base our practice on research which is less than ideal - in this case retrospective, heterogeneous research which includes both in vitro and in vivo data. This often-cited classic prosthodontic paper does however comprise a commendable clinical sample size of 1273 ETT which were followed-up in the long term, from 1-25 years. ${ }^{10}$ Contemporary prosthodontic literature continues to show support for restoring posterior ETT with crowns in order to enhance their longevity. ${ }^{11-12}$

Within this Cochrane systematic review, only one trial ${ }^{13}$ met the inclusion criteria of the review and this was judged to be at high risk of performance, detection and attrition bias and of very low quality. ${ }^{14}$ The authors of the review suggest that insufficient evidence exists to support either treatment modality and that 
clinicians must base decisions on restoring ETT on their own clinical experience, taking into account the individual circumstances and preferences of their patients.

The purpose of science and of a Cochrane systematic review is the pursuit of truth through the careful and critical analysis of evidence. A Cochrane systematic review is about evidence rather than best practice. The authors of this commentary wonder however, is there a danger that the conclusions of a Cochrane review could be misleading?

It is conceivable that dentists may rely on the word of a Cochrane review, as the highest level of healthcare evidence, to guide their clinical decision making. Likewise patients may look to Cochrane evidence for guidance on their own treatment decisions. It is possible that patients may not access treatment which is best practice due to 'insufficient evidence,' yet there exists plenty of soft evidence ${ }^{10,15}$ in support of crowning ETT, which ranges from anecdotal, expert opinion $^{3}$ to relatively robust albeit retrospective and potentially biased cohort analysis. ${ }^{9,12}$

With only one trial, which is judged to be of very poor quality, this Cochrane systematic review begs the questions - why carry out a systematic review of the literature? And in the absence of high quality, robust data, is alternative evidence not worth considering? ${ }^{16}$ Or indeed is it sensible to discontinue the review based on a lack of robust evidence?

It is noted in the methods of the systematic review that studies which made comparisons between different types of post \& cores (ie cast post \& core and crown versus direct restoration with no post) were excluded from the analysis. One may wonder why such an exclusion criterion is put in place when so much of the prosthodontic literature suggests little influence of the post \& core type on the success of restored ETT when adequate coronal tooth structure remains on ETT. ${ }^{8-10,15,17}$ Indeed, perhaps the quantity, quality and precise location of coronal tooth structure is a more important criterion for determining the success of restored ETT, although a much more difficult factor to control for in in vivo scientific studies.

The systematic review states that within the one trial that met its inclusion criteria, randomisation was achieved by a coin toss. The systematic review suggests that such a sequence generation is at low risk of bias. However, the contemporary literature suggests the contrary; that the toss of a coin can be manipulated in favour of one outcome over another and as such this method of randomisation has been largely discredited. ${ }^{18}$

Nevertheless this Cochrane systematic review of the literature highlights that the current prosthodontic literature, despite its abundance, is of weak quality in general and it stresses the pressing need for improved research methods when undertaking future research in the field of restorative dentistry.

David McReynolds and Brett Duane Dublin Dental University Hospital, Dublin, Eire

1. Dietschi D, Duc O, Krejci I, Sadan A. Biomechanical considerations for the restoration of endodontically treated teeth: a systematic review of the literature - Part 1. Composition and micro- and macrostructure alterations. Quintessence Int 2007; 38: 733-743.

2. Dietschi D, Duc O, Krejci I, Sadan A. Biomechanical considerations for the restoration of endodontically treated teeth: a systematic review of the literature, Part II (Evaluation of fatigue behavior, interfaces, and in vivo studies). Quintessence Int 2008 39: 117-129.

3. Rosen H. Operative Procedures on Mutilated Endodontically Treated Teeth. J Prosthet. Dent 1961; 11: 973-986.

4. Torbjorner A, Fransson B. Biomechanical aspects of prosthetic treatment of structurally compromised teeth. Int J Prosthodont 2004; 17: 135-141.

5. Peroz I, Blankenstein F, Lange KP, Naumann M. Restoring endodontically treated teeth with post and cores - a review. Quintessence Int 2005; 36: 737-746.

6. Ray HA, Trope M. Periapical status of endodontically treated teeth in relation to the technical quality of the root filling and the coronal restoration. Int Endod J 1995; 28: 12-18.

7. Al-Omiri MK, Mahmoud AA, Rayyan MR, Abu-Hammad O. Fracture resistance of teeth restored with post-retained restorations: an overview. / Endod 2010; 36: 1439-1449.

8. Libman W], Nicholls JI. Load fatigue of teeth restored with cast posts and cores and complete crowns. Int J Prosthodont 1995; 8: 155-161.

9. Sorensen JA, Martinoff JT. Intracoronal reinforcement and coronal coverage: a study of endodontically treated teeth. J Prosthet Dent 1984; 51: 780-784.

10. Goodacre CJ, Spolnik KJ. The prosthodontic management of endodontically treated teeth: a literature review. Part I. Success and failure data, treatment concepts. J Prosthodont 1994; 3: 243-250.

11. Skupien JA, Cenci MS, Opdam NJ, Kreulen CM, Huysmans MC, Pereira-Cenci T. Crown vs. composite for post-retained restorations: A randomized clinical trial. J Dent 2016; 48: 34-39.

12. Aquilino SA, Caplan DJ. Relationship between crown placement and the survival of endodontically treated teeth. / Prosthet Dent 2002; 87: 256-263.

13. Mannocci F, Bertelli E, Sherriff M, Watson TF, Ford TR. Three-year clinical comparison of survival of endodontically treated teeth restored with either full cast coverage or with direct composite restoration. J Prosthet Dent 2002; 88: 297-301.

14. Sequeira-Byron P, Fedorowicz Z, Carter B, Nasser M, Alrowaili EF. Single crowns versus conventional fillings for the restoration of root-filled teeth. Cochrane Database Syst Rev 2015; 9: CD009109. doi: 10.1002/14651858.CD009109.pub3.

15. Robbins JW. Restoration of the endodontically treated tooth. Dent Clin North Am 2002; 46: 367-384.

16. Ferriter $\mathrm{M}$, Huband $\mathrm{N}$. Does the non-randomized controlled study have a place in the systematic review? A pilot study. Crim Behav Ment Health 2005; 15: 111-120.

17. Morgano SM, Brackett SE. Foundation restorations in fixed prosthodontics: current knowledge and future needs. J Prosthet Dent 1999; 82: 643-657.

18. Clark MP, Westerberg BD. Holiday review. How random is the toss of a coin? CMA 2009; 181: E306-E308.

Evidence-Based Dentistry (2016) 17, 50-51. doi:10.1038/sj.ebd.6401170 